\title{
The Gradostat: a Bidirectional Compound Chemostat and its Application in Microbiological Research
}

\author{
By R. W. LOVITT AND J. W. T. WIMPENNY* \\ Department of Microbiology, University College, Cardiff, Newport Road, \\ Cardiff CF2 1TA, U.K.
}

(Received 29 September 1980; revised 1 April 1981)

\begin{abstract}
A multistage continuous culture system is described in which solutes are transferred between vessels in opposite directions simultaneously. The system, called a gradostat, produces opposing solute gradients and is a good laboratory model of many natural microbial ecosystems in which solute gradients are important. Theoretical predictions concerning solute transfer were confirmed under steady-state and non steady-state conditions, using a coloured dye. Paracoccus denitrificans grew anaerobically in the gradostat at the intersection between opposing gradients of succinate and nitrate. Opposing gradients of glucose and oxygen separated the growth of a Bacillus sp. (a facultative anaerobe) and Clostridium butyricum (an obligate anaerobe). Viable counts for both species fell exponentially away from their growth positions at the ends of the gradostat. The potential value of the gradostat and possible alternative conformations are discussed.
\end{abstract}

\section{INTRODUCTION}

The majority of microbial ecosystems are spatially heterogeneous, particularly in terms of the distribution of solutes whose concentrations govern the growth rate and the type of metabolism exhibited by the micro-organisms present. Few laboratory models attempt to simulate structured ecosystems. Most laboratory investigations have relied on the use of single-stage homogeneous chemostats which cannot reproduce the vectorial characteristics of solute gradients. One example of a heterogeneous laboratory model is the percolating column (Bazin \& Saunders, 1973). A two-dimensional gel-stabilized model system has been used to determine the habitat requirements of different organisms (Caldwell \& Hirsch, 1973). Multistage continuous culture systems have been used to investigate the degradation of oil (Jannasch \& Mateles, 1974; Pritchard et al., 1976) and the nitrification and denitrification of effluents (Hawkes, 1977). A three-stage system has been proposed for the sequential degradation of complex wastes such as coke-oven liquor (Abson \& Todhunter, 1961). A complex system was devised to model bidirectional exchange of nutrients found in the estuarine ecosystem (Cooper \& Copeland, 1973). This model consisted of five linked and stirred vessels, with fresh water, representing the river water input, flowing in ane end. At the opposite end salt water was introduced, representing the tidal inflow of sea water. This system established salinity gradients and resulted in the development of a classic estuarine planktonic flora. Independently, we have developed and briefly described a similar system, termed the gradostat (Lovitt \& Wimpenny, 1979). This system is based on multistage chemostat principles with the innovation that it uses bi-directional flow of media to generate opposing solute gradients. The present paper gives a complete description of the gradostat with two examples of its use and value in microbial ecological studies.

\section{METHODS}

Design, construction and operation of the gradostat. The gradostat consists of a linked series of magnetically stirred 1 litre glass vessels (Jobling Laboratory Division, Stone, Staffs.) containing approximately $665 \mathrm{ml}$ 


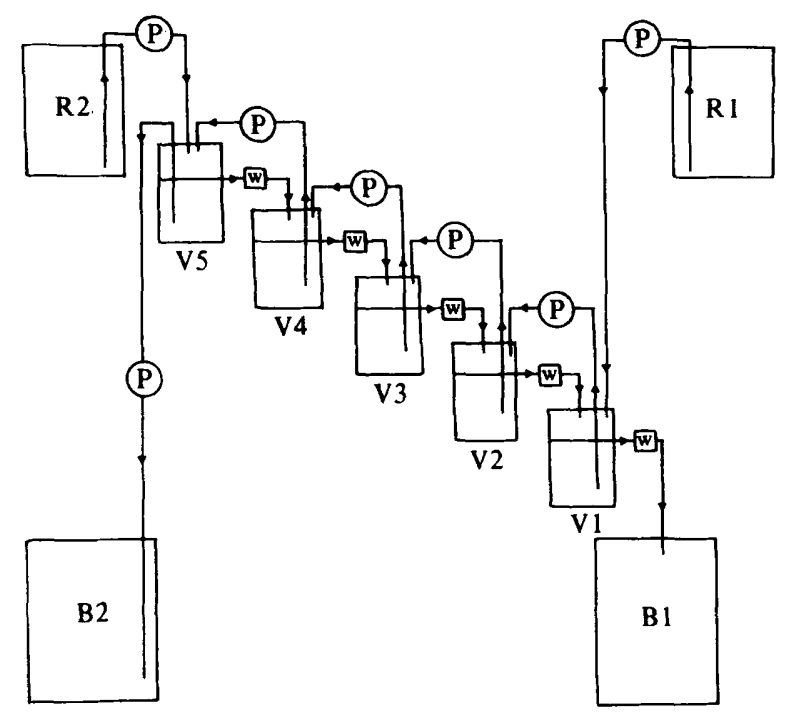

Fig. 1. Schematic representation of the gradostat. The five culture vessels (V1 to V5) are fed with medium from reservoir R1 in an upward direction, with transfer between the vessels by a series of pumps (P). Medium from reservoir R2 is fed down the sequence of vessels over a series of weirs (w). B1 and $\mathrm{B} 2$ are the effluent culture vessels.

medium (Fig. 1). The temperature and rates of stirring are controlled by base units constructed by the Faculty of Science Electronic Workshop, University College, Cardiff. Media are pumped from their respective reservoirs into the two end growth vessels, flow through each vessel, and are collected in waste culture receivers at each end of the system. In the downward direction, flow between the vessels, over a series of weirs, is controlled by gravity. In the upward direction, a multichannel peristaltic pump (Technicon Autoanalyser, Technicon Instruments, New York, U.S.A.) transfers media between the vessels. The vessels and reservoirs are connected by Tygon tubing (Baird \& Tatlock, London) or black butyl rubber tubing (Esco Rubber Co., London). The highest vessel (vessel 5) contains an inoculation port and the lowest vessel (vessel 1) is supplied with a filtered air input. Each vessel is equipped with a sample tube, magnetic follower, temperature probe and medium input and output lines. The output tubes of the weirs from each vessel dip into the culture medium of the next vessel to eliminate gas exchange between adjacent vessels. The system is sterilized dry, by autoclaving at $121^{\circ} \mathrm{C}$ for $20 \mathrm{~min}$. The gradostat is inoculated by transferring a $5 \mathrm{I}$ culture to the highest vessel and allowing this to fill all the vessels by gravity. To sample each vessel two consecutive $20 \mathrm{ml}$ samples are withdrawn through the sampling line using a sterile disposable syringe. The first sample is discarded since it contains culture from the sample line dead space.

Organisms and media. Bacillus sp. strain 11 (Microbiology Department, University College, Cardiff) was maintained on nutrient agar slopes. Clostridium butyricum (NCIB 7423) was maintained on BG broth (see below) in anaerobic jars. Paracoccus denitrificans, obtained from Dr Lucille Smith (Biochemistry Department, Dartmouth College Medical School, Hanover, N.H., U.S.A.), was maintained on Dorset egg (Oxoid) slopes at room temperature in the dark.

Medium A contained, in glass distilled water $\left(\mathrm{gl}^{-1}\right): \mathrm{KH}_{2} \mathrm{PO}_{4}, 4 ; \mathrm{K}_{2} \mathrm{HPO}_{4}, 6 ; \mathrm{Na}_{2} \mathrm{MoO}_{4} .2 \mathrm{H}_{2} \mathrm{O}, 0 \cdot 15$; $\mathrm{MgSO}_{4} .7 \mathrm{H}_{2} \mathrm{O}, 0.2 ; \mathrm{CaCl}_{2} .6 \mathrm{H}_{2} \mathrm{O}, 0.05 ; \mathrm{MnSO}_{4}, 0.0005$; and ferric citrate solution $\left(18 \mathrm{~g} \mathrm{FeSO}_{4} .7 \mathrm{H}_{2} \mathrm{O}\right.$ and $10 \mathrm{~g}$ citric acid in $100 \mathrm{ml} \mathrm{H}_{2} \mathrm{O}$ ), $0.05 \mathrm{ml} \mathrm{l}^{-1}$. The $\mathrm{pH}$ was adjusted to 7.5 before autoclaving. In addition medium A1 contained $5 \mathrm{~g} \mathrm{NaNO}_{3} \mathrm{l}^{-1}$ and medium A2 $13.5 \mathrm{~g}$ sodium succinate $\mathrm{l}^{-1}$.

Medium B contained, in distilled water ( $\mathrm{g}^{-1}$ ): peptone (Difco), 2 ; yeast extract (Difco), $2 ; \mathrm{KH}_{2} \mathrm{PO}_{4}, 5 \cdot 4 ; \mathrm{KOH}$, 4.4: and Antifoam RD (Dow Corning, Barry, Wales), $1.5 \mathrm{ml} \mathrm{l}^{-1}$. The $\mathrm{pH}$ was adjusted to 7.8 before autoclaving. For Medium BG, glucose was added to give $5 \mathrm{~g}^{-1}$; for BG agar (BGA), agar (Difco) was added to $15 \mathrm{~g}^{-1}$.

All the media were sterilized in 151 quantities contained in 201 aspirators at $121^{\circ} \mathrm{C}$ for 40 min, except that glucose was sterilized separately as a concentrated solution at $121^{\circ} \mathrm{C}$ and added after cooling.

Cell counts. Total counts were obtained using a Thoma counting chamber (Gallenkamp), as described by Postgate (1969), on samples diluted with $4 \%(\mathrm{v} / \mathrm{v})$ formalin solution.

Viable counts in the Bacillus sp./C. butyricum mixed culture were estimated after $7 \mathrm{~d}$ incubation at $37^{\circ} \mathrm{C}$. Aerobic incubation on BGA plates gave Bacillus sp. counts whilst anaerobic incubation on the same medium allowed both organisms to grow. The two species were differentiated by colonial morphology. Most probable 
number (MPN) counts were performed in liquid BG medium. Clostridia were detected by low pH values (5.5), sediment formation and gas production in contrast to growth of the Bacillus sp. As the C. butyricum counts were always lower than Bacillus sp. counts on plates it was assumed for MPN calculation that a C. butyricum positive was also a Bacillus sp. positive.

Respiration measurements. Cultures were harvested by centrifuging at $20000 \mathrm{~g}$ for $20 \mathrm{~min}$ at $4{ }^{\circ} \mathrm{C}$. Cells were washed in 10 mM-potassium phosphate buffer ( $\mathrm{pH} \mathrm{7.4),} \mathrm{recentrifuged,} \mathrm{and} \mathrm{suspended} \mathrm{in} \mathrm{the} \mathrm{same} \mathrm{buffer.} \mathrm{Oxygen}$ uptake measurements were made polarographically at $37^{\circ} \mathrm{C}$ as described by Lloyd \& Brookman (1967), using an oxygen electrode (Rank Industries, London). The rate of oxygen uptake $\left(Q_{\mathrm{O}_{2}}\right)$ was expressed as $\mathrm{nmol} \mathrm{O}_{2}(\mathrm{mg}$ protein) ${ }^{-1} \min ^{-1}$.

Cell density. Culture turbidity was used as an index of cell density. The sample was diluted in $10 \mathrm{~mm}$-phosphate buffer (pH 7.4) to a value below 0.8 and read at $550 \mathrm{~nm}$ in an MSE Spectro-plus spectrophotometer.

Chemical determinations. Glucose was estimated by the glucose oxidase method (Raabo \& Terkildsen, 1960) using Sigma assay kit 510.

Nitrate was estimated colorimetrically using brucine sulphate (American Public Health Association, 1971). Nitrite was measured colorimetrically using the Griess-Ilosvay reagents (Mackereth et al., 1978). Volatile and non-volatile fatty acids were determined by gas-liquid chromatography. A $2 \mathrm{~m} \times 4 \mathrm{~mm}$ i.d. glass column packed with $5 \%(w / w)$ FFAP on Chromosorb G80-100 mesh (AW-DCMS; Jones Chromatography, Llanbradach, S. Glamorgan, Wales) was used in a Pye series 104 chromatograph, using argon as a carrier gas. Volatile primary and secondary alcohols and fatty acids were determined directly after extraction with diethyl ether from $4 \mathrm{ml}$ of culture.

Keto- and dicarboxylic acids were determined by gas-liquid chromatography as their methyl esters. The methyl esters were prepared by reacting $1 \mathrm{ml}$ of culture medium with $14 \%(\mathrm{w} / \mathrm{v})$ boron trifluoride in methanol (Holdeman et al., 1972).

Protein was estimated using the method of Lowry and the total protein content of whole cells was measured after alkaline pretreatment (Herbert et al., 1971).

\section{THEORY}

The equations describing solute transfer in the gradostat were derived by Mr D. J. Harris (Department of Pure Mathematics, University College, Cardiff).

To determine the concentration $x_{n}$ of a solute in the $n$th vessel the following differential equation applies:

$$
V \frac{\mathrm{d} x}{\mathrm{~d} t} n=u x_{n-1}+v x_{n+1}-(u+v) x n \quad(n=1,2 \ldots N)
$$

where $u$ and $v$ are media flow rates through the vessels, which are constant in this case, and $V$ is the volume of the vessel.

If $x_{0}=a$ and $x_{n+1}=b$, which are the concentrations of a different solute in each reservoir, and initial conditions are such that $x_{n}=0$ at time $t=0(n=1,2 \ldots N)$, then solving the differential equation gives

$$
x_{n}=\left(\frac{u}{v}\right)^{\frac{n}{2}} \frac{1}{N+1} \sum_{k=1}^{N} \frac{C_{k}}{\alpha_{k}}\left(\mathrm{e}^{\alpha_{k} t}-1\right) \sin \left(\frac{n k \pi}{N+1}\right)
$$

where

$$
\begin{gathered}
\alpha_{k}=2 \lambda \cos \frac{k \pi}{N+1}+\mu, C_{k}=2 \lambda\left\{a+b\left(\frac{v}{u}\right)^{\frac{N+1}{2}}(-1)^{k+1}\right\} \sin \left(\frac{k \pi}{N+1}\right), \\
\lambda=-\frac{\sqrt{u+v}}{V} \text { and } \mu=\frac{-u+v}{V}
\end{gathered}
$$


Equation (2) defines the concentrations of a solute in a particular vessel at any time after pumping commences. However, as $t$ tends to $\infty$, the system tends to a steady state given by

$$
x_{n}=E(u / v)^{n}+F
$$

where

$$
E=(a-b) /\left\{1-(u / v)^{N+1}\right\} \quad \text { and } \quad F=\left\{b-a(u / v)^{N+1}\right\} /\left\{1-(u / v)^{N+1}\right\}
$$

Where the flow rates $u$ and $v$ are equal, this simplifies to

$$
x_{n}=A+(n+1) B
$$

where

$$
A=\{(N+2) a-b\} /(N+1) \quad \text { and } \quad B=(b-a) /(N+1)
$$

\section{RES ULTS}

The flow of dye into the gradostat. The distribution of methylene blue was followed in the gradostat to ensure that the system behaved as theory predicted. The four vessels and one reservoir of a four-element gradostat were filled with distilled water; the other reservoir contained a solution of methylene blue having an $A_{600}^{1 \mathrm{~cm}}$ of 3.05. The pump rates were in the range $195 \pm 6 \mathrm{ml} \mathrm{h}^{-1}$ and the volume of liquid in each vessel was in the range $665 \pm 5 \mathrm{ml}$. Dye concentrations were estimated in each vessel as a function of time. Observed values and theoretical values obtained by applying the relevant equations corresponded well (Fig. $2 a$ ). Steady-state concentrations of the dye were close to values predicted by equation 4 (Fig. $2 b$ ). A good agreement was observed between the two considering the errors of pumping rate $( \pm 3 \%)$ and vessel volumes $( \pm 0.2 \%)$. It was concluded that the model functioned as predicted both under steady-state and non steady-state conditions. Any material (cells or solutes) which is homogeneously dispersed in any one vessel is transferred according to the equations shown above. At steady state there is a linear gradient of cells or solutes from source to sink provided that all flow rates and all vessel volumes are equal. This is easy to see in the case of material
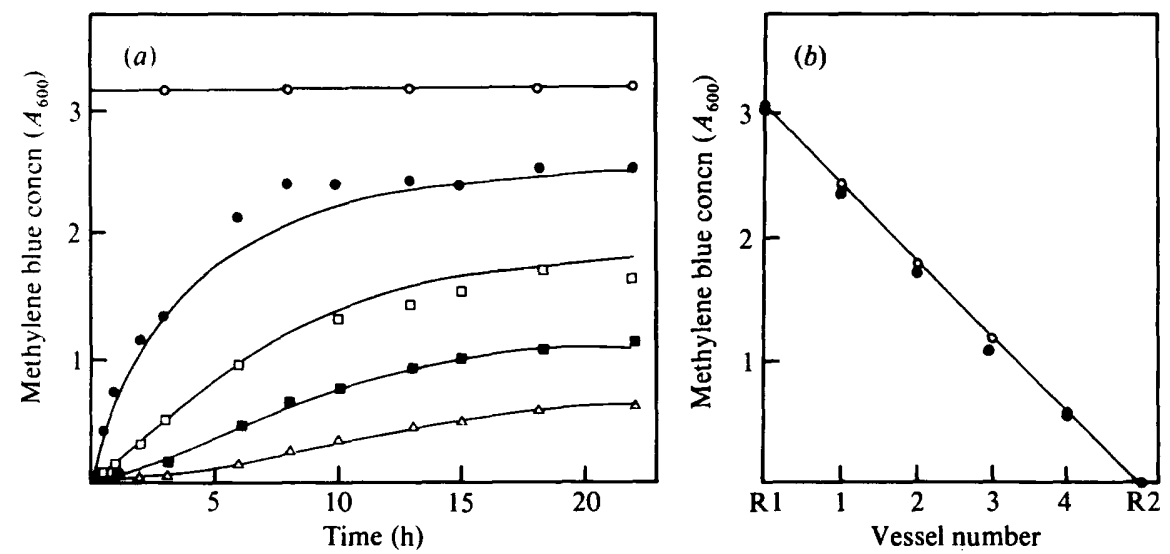

Fig. 2. Transfer of the dye methylene blue in the gradostat. Initially all the vessels and reservoir R2 contained distilled water, while reservoir RI contained methylene blue. (a) Time course. The theoretical values are shown by the continuous lines; the observed values are represented by the individual plotted symbols: reservoir RI $(O)$; vessel $1(O)$; vessel $2(\square)$; vessel $3(\square)$; vessel $4(\Delta)$. (b) Steady-state conditions: theoretical $(O)$ and observed $(O)$ values. 

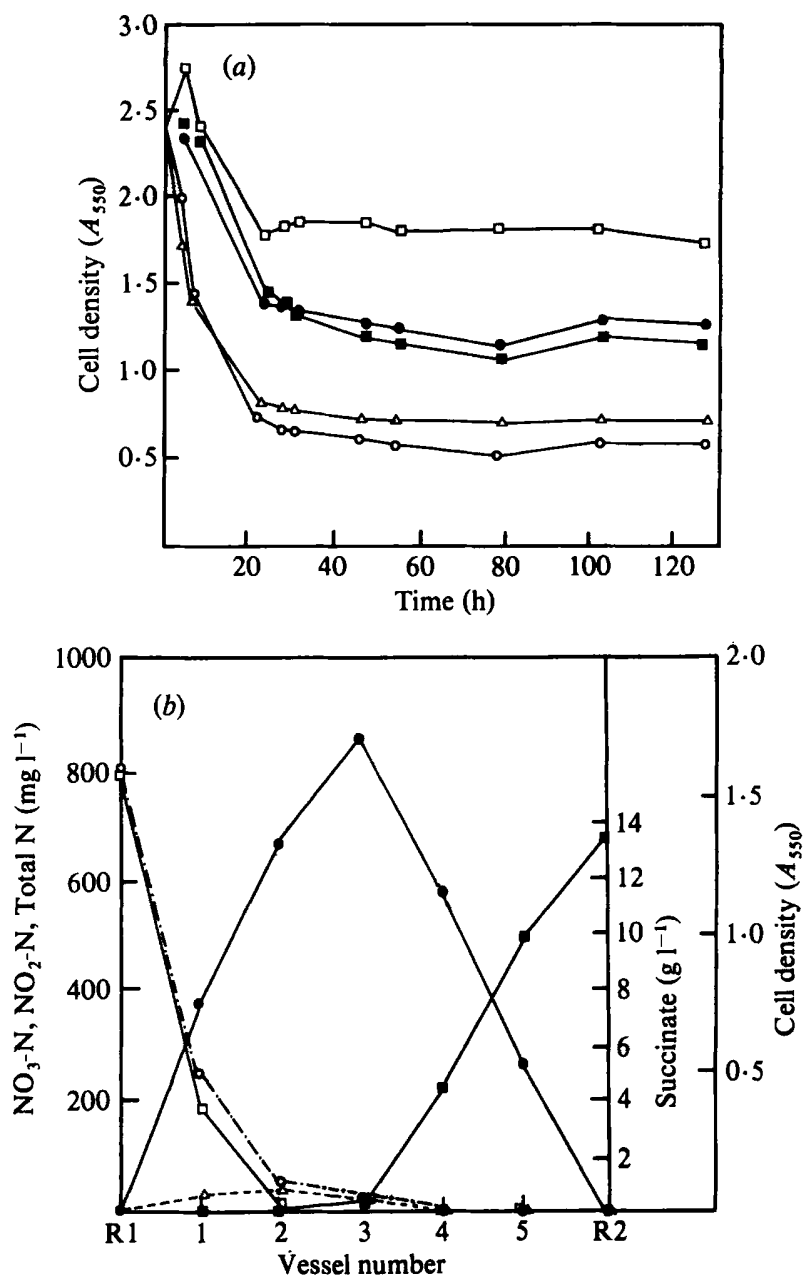

Fig. 3. Growth of Paracoccus denitrificans in opposing gradients of succinate and nitrate in the gradostat. (a) Time course for growth in each vessel, from inoculation: cell density in vessel $1(\Delta)$, vessel $2(O)$, vessel $3(\square)$, vessel $4(\square)$ and vessel $5(O)$. (b) Steady-state conditions: cell density $(O)$; concentrations of succinate $(\square)$, nitrate $\left(\mathrm{NO}_{3}-\mathrm{N}\right)(\square)$, nitrite $\left(\mathrm{NO}_{2}-\mathrm{N}\right)(\triangle)$ and nitrate plus nitrite (total $\mathrm{N})(\mathrm{O}) . \mathrm{R} 1$ and $\mathrm{R} 2$ denote the medium reservoirs.

present in one reservoir if it is transferred unchanged down the array of vessels. If cell growth, or the production of a solute by a cell, occurs in one vessel alone there will be a linear gradient away from that vessel in both directions.

Growth of Paracoccus denitrificans in opposing gradients of nitrate and succinate. The simplest experiment to test the gradostat was to grow a single organism in opposing gradients of two different nutrients. A five-element gradostat was inoculated with a culture of $\boldsymbol{P}$. denitrificans grown in medium A plus both succinate and nitgate. Nitrate entered the system as medium A1 from reservoir 1 to vessel 1 whilst succinate entered the system as medium A2 from reservoir 2 to vessel 5 . The volume of medium in the vessels was $665 \pm 5 \mathrm{ml}$ and the flow rates were $106 \pm 3 \mathrm{ml} \mathrm{h}^{-1}$. The temperature was maintained at $30^{\circ} \mathrm{C}$. The concentration of $P$. denitrificans in each vessel was followed with time (Fig. $3 a$ ). A steady state was established after $48 \mathrm{~h}$ in all five culture vessels, although slight fluctuations in turbidity were subsequently seen. Steady-state substrate and absorbance values after $128 \mathrm{~h}$ are shown in Fig. $3 b$.

Growth of $P$. denitrificans was at a maximum in the central vessel (vessel 3) of the five-element gradostat; however, the concentrations of succinate and nitrogen source were 


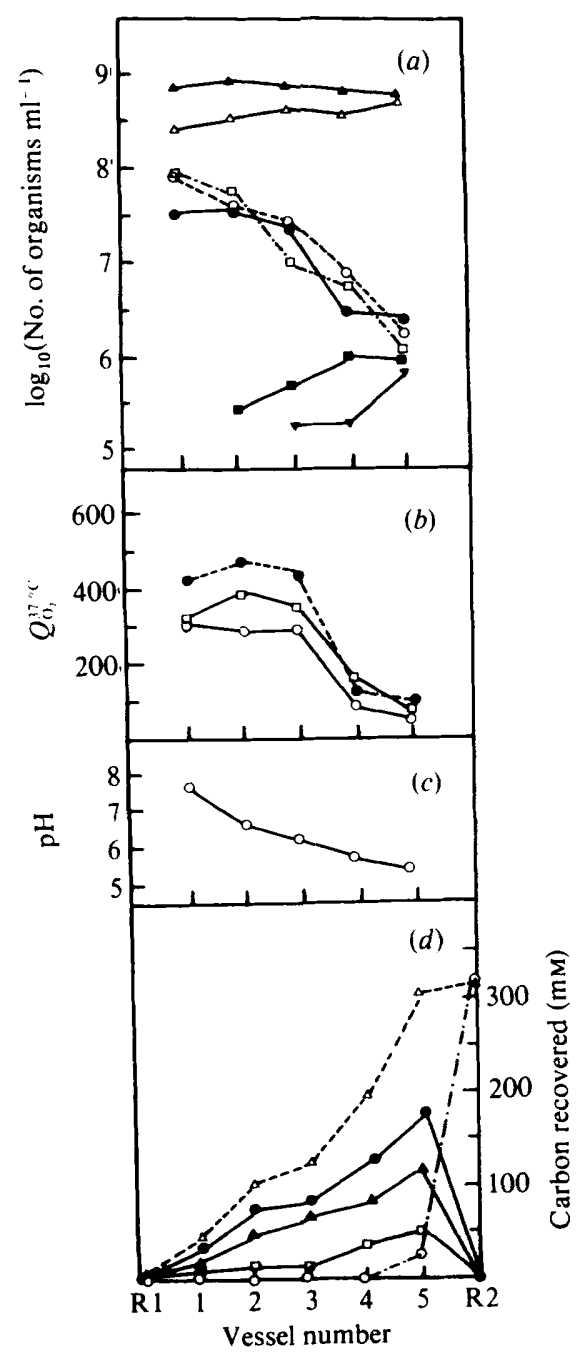

Fig. 4. Growth of a mixed culture of Bacillus sp. and Clostridium butyricum in opposing gradients of oxygen and glucose in the gradostat. R1 and R2 denote the medium reservoirs. (a) Cell counts: total particle counts $(\Delta)$; total cell count $(\Delta)$; viable count of Bacillus sp. on BG agar incubated aerobically (O). and anaerobically ( $\square$ ), and as MPN counts on BG agar incubated anaerobically (O); clostridia as MPN counts in liquid medium BG ( $\mathbf{D}$ ) and incubated anaerobically on BG agar $(\boldsymbol{\nabla}) .(b) \mathrm{Q}_{0}$ values [nmol $\mathrm{O}_{2} \min ^{-1}$ (mg protein $\left.)^{-1}\right]$ for the mixed population from each vessel: endogenous (O); plus

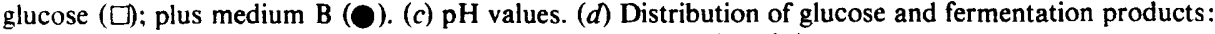
glucose $(O)$; butyrate $(O)$; acetate $(\Delta)$; butanol $(\square)$; total carbon $(\triangle)$.

evidently not exactly balanced, as more growth was seen in vessel 2 than in vessel 4 . This conclusion is borne out by the distribution of solutes away from vessel 3 . For example the concentration of succinate fell linearly from its source in $\mathbf{R} 2$ to vessel 3, whilst nitrate was reduced in vessel 2 as well as in vessel 3. These observations suggest that some reductant entered vessel 2 leading to additional cell proliferation.

Growth of a mixed culture of a Bacillus sp. and Clostridium butyricum. A mixed culture of a Bacillus sp. (a facultative anaerobe resembling B. cereus) and Clostridium butyricum (an obligate anaerobe) was inoculated into a five-element gradostat and grown in opposing 
gradients of glucose and oxygen. Medium BG was pumped into vessel 5 (anaerobic end) and medium B into the aerated $\left(11 \mathrm{~min}^{-1}\right)$ vessel 1 (aerobic end). Steady-state conditions were reached after $9 \mathrm{~d}$ (Fig. 4).

A pH gradient developed across the array from 7.7 in vessel 1 to 5.5 in vessel 5 (Fig. 4 c). Glucose was detected only in vessel 5 and it was here that greatest amounts of acetate, butyrate and butanol were found (Fig. $4 d$ ). The concentrations of these fermentation products fell in an approximately linear fashion from vessel 5 to vessel 1 .

The ability of washed cells to oxidize constituents of medium B, glucose or endogenous substrates was tested. $Q_{\mathrm{O}}$, values were high in the mixed population in vessels 1,2 and 3 and low in vessels 4 and 5 (Fig. $4 b$ ). Endogenous respiration in cells from vessel 1 was not stimulated by glucose.

Total particle and cell counts (Fig. $4 a$ ) as well as turbidity measurements (not shown) indicated that the cell population density was approximately constant from one end of the array to the other. Viable counts for the Bacillus sp. were performed in three different ways, which all suggested that the number of viable cells declined approximately exponentially from the aerobic end to the anaerobic end of the array (Fig. $4 a$ ). These kinetics suggest that a proportion of the population was killed by products generated at the anaerobic end. The viable population of $C$. butyricum was determined in two ways. The numbers were highest at the anaerobic end and declined towards the aerobic end. No precautions were taken to exclude oxygen from the diluent for anaerobic viable counts and it is likely that the counts for $C$. butyricum underestimated the true values in the gradostat.

\section{DISCUSSION}

The ubiquity of spatially organized microbial ecosystems in nature has prompted us to develop laboratory models which incorporate solute concentration gradients. The gradostat is one such model and consists of a series of interconnecting stirred homogeneous fermenter vessels, with reservoirs and sinks at each end of the array. It is possible with this device to establish opposing solute gradients. The gradostat is an open system which can be used to investigate steady-state or transient behaviour. In this respect it resembles other open continuous culture systems and is quite different from gel-stabilized model systems (Wimpenny et al., 1981). The virtue of an open system is that it is possible to analyse the kinetic behaviour of systems, especially under steady-state conditions. The use of stirred fermenter vessels allows analysis of solutes, the determination of viable and non-viable cell concentrations, and the collection and analysis of cells.

Equations defining the transfer of dissolved or suspended material through the gradostat were solved and the model was tested experimentally using a dye. Under steady-state conditions there is a concentration gradient from source to sink when all the flow rates are equal and the volumes of each vessel are the same. It is possible to generate other diffusion gradients using different combinations of vessel volume and flow rates. Experiments with Paracoccus denitrificans demonstrated the growth of an organism at an interface between two essential nutrients flowing towards one another. Both nutrients were present in the third vessel of a five-vessel system and this became a source for cells which were approximately linearly distributed away from this point to each sink. Conversely, vessel 3 was a sink for both solutes and their concentrations fell linearly from each reservoir to this sink.

Growth is not necessarily possible in each habitat provided by the gradostat, as is clear from the experiment with $P$. denitrificans. The existence of separate habitats, however, led to the separation of growth in the experiment with a Bacillus sp. and Clostridium butyricum. The latter, a strict anaerobe, requiring glucose and a reducing environment, grew best at one end of the array whilst the former, a facultative anaerobe, grew at the expense of components in the complex medium, using oxygen as electron acceptor, at the other end. The distribution of viable cells away from these niches did not follow the calculated values from source to sink 
described above. In fact both species showed an exponential fall in viability, suggesting that environments other than their own were actively toxic to each organism.

Modifications to the gradostat are possible and depend on the problem under investigation. The conformation of the system may be changed by blanking off one end to produce a solute-exchange pattern similar to that of a sediment or a microbial film. Cells and sterile medium could be separated by semi-permeable membranes. The movement of cells and medium may thus be differentially regulated, and the cell compartments could themselves be open or closed. Two- or three-dimensional gradostats could be constructed. Any number of compartments could be incorporated into the gradostat. We have chosen an odd number (five) for biological experiments because it is considered an advantage for the system to have a centre. The more vessels there are, the greater is the resolution of the system; however, the number of pumped channels and the overall complexity also increase with a consequent risk of mechanical failures.

Potential applications of the gradostat embrace many areas of microbial ecology and genetics. Any problem in which adjacent spaces in nature can be linked by the transfer of solutes from one region to another can be modelled constructively in the gradostat. Examples of such problems include an examination of the main nutrient cycles such as the sulphur or nitrogen cycles. The response of micro-organisms to xenobiotics or to any antagonist may also be examined since the gradostat can provide compartments in which growth occurs but at the same time cells are transferred towards higher inhibitory concentrations of the agents concerned. Under these conditions genetic selection may operate. It should also be possible to investigate plasmid transfer by choosing appropriate gradostat conditions.

One of us (R.W. L.) gratefully acknowledges the receipt of a research studentship from Esso Research Ltd.

\section{REFERENCES}

Abson, J. W. \& Todhunter, R. K. (1961). Plant for continuous biological treatment of carbonisation effluents. Society of Chemical Industry Monograph 12. 147 .

American Public Health association (1971). Standard Methods for the Examination of Water and Waste Water, 13th edn, pp. 461-464.

Bazin, M. J. \& SAunders, P. T. (1973). Dynamics of nitrification in a continuous flow system. Soil Biology and Biochemistry 5, 531-543.

Caldwell. D. E. \& Hirsch, P. (1973). Growth of microorganisms in two-dimensional steady state diffusion gradients. Canadian Journal of Microbiology 19, 53-58.

COOPER, D. G. \& Copeland, B. J. (1973). Responses of a continuous series of estuarine microecosystems to point-source input variations. Ecological Monographs 43, 213-236.

HAWKES, H. A. (1977). Eutrophication of rivers, effects, causes and control. In Treatment of Industrial Effluents, pp. 159-192. Edited by A. G. Callely, C. F. Forster \& D. A. Stafford. London: Hodder \& Stoughton.

Herbert, D., Phipps, P. J. \& Strange, R. E. (1971). Chemical analysis of microbial cells. Methods in Microbiology 5B, 209-344.

Holdeman, L. V.. Cato, E. P. \& Moore, W. E. C. (1972). V.P.I. Anaerobe Laboratory Handbook. Blacksburg, Virginia: Virginia Polytechnic Institute and State University.

JanNasCh, H. W. \& Mateles. R. I. (1974). Experi- mental bacterial ecology studied in continuous culture. Advances in Microbial Physiology 11, 161-209.

Lloyd, D. \& Brookman, J. S. G. (1967). An oxygen electrode reaction vessel. Biotechnology and Bioengineering 9, 271-272.

Lovirt, R. W. \& Wimpenny, J. W. T. (1979). The gradostat: a tool for investigating microbial growth and interactions in solute gradients. Society for General Microbiology Quarterly 6, 80.

Mackereth, F. J. H., Heron, J. \& Talling, J. F. (1978). Water analysis. Freshwater Biological Association Scientific Publication No. 36.

Postgate, J. R. (1969). Viable counts and viability. Methods in Microbiology 1, 611-628.

Pritchard, P. M., Ventullo, R. M. \& Suflita, J. M. (1976). The microbial degradation of diesel oil in a multistage continuous culture system. In Proceedings of the 3rd International Biodegradation Symposium, pp. 67-78. Edited by J. MilesSharppey \& A. M. Kaplan, London: Applied Science Publishers.

RaAbo, E. \& Terkildsen, T. C. (1960). On the enzymatic determination of blood glucose. Scandinavian Journal of Clinical and Laboratory Investigation 12, 402-407.

WimpenNy, J. W. T., Coombs, J. P., LovitT, R. W. \& WhITTAKER, S. G. (1981). A gel-stabilized model for investigating microbial growth in spatially ordered solute gradients. Journal of General Microbiology 127, 277-287. 